\title{
ANALYSIS OF THE SPATIAL-TEMPORAL DYNAMICS OF THE MISSAHOHE CLASSED FOREST IN SOUTHERN TOGO
}

\author{
K.G. Eric AGBESSI ${ }^{1 *}$, Eric FOTSING ${ }^{2}$, B. Dodé JOHNSON ${ }^{3}$, Fousséni FOLEGA ${ }^{4}$, Gabriel H. \\ SEGNIAGBETO $^{4}, \mathrm{H}$. Maléki BADJANA ${ }^{4}$, and Michel TCHOTSOUA ${ }^{1}$ \\ ${ }^{1}$ University of Ngaoundere, ${ }^{2}$ University of Dschang, ${ }^{3}$ AfricanRegional Institute for Geospatial Information Science \\ and Technology (AFRIGIST), ${ }^{4}$ Université de Lomé \\ https://doi.org/10.35410/IJAEB.2021.5606
}

\begin{abstract}
In order to have reliable information on the extent of forest degradation and deforestation for adequate decision-making, the spatial and temporal dynamics of the protected area, Missahohe Classified Forest, were studied from Landsat imagery for the years 1986, 2001 and 2018. A diachronic analysis of the land cover (between 1986 and 2001, on the one hand, and 1986 and 2018 on the other hand) was carried out to analyze ecosystems dynamics. The drivers of forest degradation and deforestation linked to the anthropogenic pressure observed following the invasion of the protected area in the 1990s have been identified. A supervised classification was carried out by applying the "maximum likelihood" algorithm under the ENVI 5.1 software. The overall accuracy of the resulted maps measured from the Kappa index vary from 0.8 to 0.87 . The conversions experienced by the different units of land use were analyzed. This analysis shows that forest strata decreased from 1432 ha to 1221.57 ha between 1986 and 2018, a loss of about 210 ha, particularly to crops and human settlements that did not exist in 1986. Riparian forests and dense forests are the forest strata that have experienced more regression over the past three decades (from 28.73\% in 1986 to 3\% in 2018 and from 24.63\% in 1986 to $22 \%$ in 2018 respectively). While the annual rate of deforestation is estimated at $0.5 \%$. Agriculture, logging, carbonization and honey harvesting are the four main factors of vegetation cover alteration in the study area. All of these results are necessary for the choice of the appropriate protection strategy option for the protected area.
\end{abstract}

Keywords: GIS-remote sensing, deforestation, human disturbance, forest planning.

\section{INTRODUCTION}

Covering an area of 56,600 $\mathrm{km} 2$, Togo has very diverse ecosystems, including both terrestrial and marine ecosystems. According to studies by Adjonou et al (2013), and Kokou (2005), terrestrial ecosystems are made up of semi-deciduous forests, dry forests, clear forests, gallery and riparian forests, and Guinean and Sudanese savannahs. Lake ecosystems include lagoons, artificial or natural, temporary or permanent ponds. The underwater flora is very poorly known, with the exception of algae, of which a few beach-rock stands have been the subject of summary inventories for educational purposes. The marine fauna is rich. There are migratory species, notably mammals (whales, dolphins, etc.) and reptiles (turtles). The diversity of ecosystems has favoured a great variety of flora and fauna in Togo. Thus, the Togolese flora includes 3491 
Vol. 06, No. 01;2021

ISSN: $2456-8643$

terrestrial species and 261 aquatic species representing all the systematic groups currently recorded on the national territory. Only one plant species, Phyllanthus rouxii (Euphorbiaceae) growing on the ferruginous hills north of Bassar is reported as endemic. Several species are threatened with extinction, endangered or vulnerable. The inventory of the Togolese fauna has identified 3476 species including 2312 terrestrial species, 1146 aquatic species and 18 domestic terrestrial species (Mammals, Birds); three species of amphibians are endemic to Togo. Three species of amphibians are endemic to Togo: Conrauaderooi in the semi-deciduous forests of Kloto and Missahohe (Plateaux Region), Aubriasubsubgillata in Kovié (Maritime Region), Bufo togoensis in the Adélé Massif (Central Region).

Four species of migratory marine turtles frequent the Togolese coasts either to lay eggs (Chelonia mydas, Lepidochelysolivacea, Dermochelys coriacea) or to feed (Erethmochelysimbricata). Dolphins and whales are also present in Togolese marine waters (Ségniagbeto, 2013). In certain bodies of water spread over the territory, crocodiles, hippopotamuses and manatees, protected species, are recorded.

It is thus to sustainably manage this biodiversity that the French Governor General Albert LEBRUN took adequate initiatives to limit degradation due to the abusive exploitation of forest resources in Togo (decree of 5 February 1938 on the organization of the forest regime in Togo.) Eighty-three (83) state-owned natural sites covering $14 \%$ of the national surface area (MERF, 2001) and which constitute the main part of the national system of protected areas in Togo were thus created between 1939 and 1957. The protected areas that have been subjected to anthropic pressure since the time of Albert LEBRUN have since then constituted true habitats for many species, thus constituting, like other countries, a cornerstone for the conservation of both animal and plant biodiversity. In the face of population growth and the accelerated degradation of natural resources, these protected areas have become the only habitat for many animal and plant species (Van de Wegh et al., 2001); and the only hope left to prevent the definitive disappearance of the many threatened or endemic species (Dudley, 2008). The socio-political crisis that Togo experienced in the 1990s during the democratic transition led to the invasion of these protected areas and accelerated the regression of forest areas (MERF, 2000). Consequences include intrusion into certain protected areas (MERF, 2014), abusive exploitation of woody species and illegal hunting. The need for the country to rationally manage its biodiversity has led it to develop and validate in 2011 a forest policy whose main objective is to restore the balance of forest ecosystems.

The Missahohe Classified Forest (FCM), which today appears as one of Togo's protected areas, whose floristic composition and vegetation physiognomy testify to the existence of a true semideciduous forest (MERF, 2003), remains highly invaded and highly threatened by overexploitation of forest resources, extensive agriculture and increased poaching despite the efforts made for biodiversity conservation. These practices profoundly disturb the balance of the ecosystem of the protected area (Adjonou, 2010). It is therefore important to analyse the impacts of these ever-increasing anthropogenic pressures on the conservation and vegetation dynamics of the protected area. The use of remote sensing and geographic information systems (GIS) is therefore appropriate for the analysis, description and understanding of biophysical processes (Rifai \&al., 2018; Ernoul\&al., 2012) that influence the dynamics of plant ecosystems. The 
Vol. 06, No. 01; 2021

ISSN: $2456-8643$

choice of remote sensing and GIS tools is therefore essential to provide decision-makers and other key stakeholders in the management of this protected area with decision-support tools to guide choices, manage the classified forest and monitor its dynamics from a georeferenced database.

\section{MATERIAL AND METHODS}

\subsection{Study area}

The present study took place in Togo and covered the Missahohé classified forest (FCM) situated between $6^{\circ} 54$ and $7^{\circ} 55$ North and $0^{\circ} 34$ and $0^{\circ} 38$ East with an area of 1487.2 ha approximately (Figure 1). It is erected as a protected area in accordance with decree No. 185-53 / EF of March 17, 1953, signed by the Governor of France Overseas L. Pechoux. The classified forest of Missahohé is divided essentially by four cantons (Agomé, Hanyigba, Agome-Tomégbé and Kouma) and limited to the North by the villages of Tokpli, Konda, Adamé; to the south by the villages of Yoh, Kusuntu and Hanyigba Dougan; to the west by the villages of HanyigbaTodji, Agomé-Tomégbé and Anédi (MERF, 2010) .The relief of the Missahohé classified forest is very rugged. It has an altitude varying between 331 and 800 metres with sometimes very marked cliffs. Their longitudinal profiles indicate steep slopes $(45.1 \%)$ which in some places cause falls and landslides. Many rivers are present and are, for the most part, small streams draining ravines. The rainfall curve of the Kouma-Konda station, a village located at the north-western limit of the classified forest, has a bimodal appearance. It has a subequatorial climate with a single rainy season, from February to November, interrupted by a decrease in rains in August. The months of June, July, September and October are the rainiest. The average annual rainfall is $1750 \mathrm{~mm}$. It is a Guinean mountain climate with a dry season of about 2 months. (MERF, 2010.)

According to Sebabe (2010), in the Missahohe Classified Forest, duikers, monkeys, rodents such as the Gambian rat, aulacode and hare can be distinguished. Among the avian fauna of the forests are Poicephalus robustus, Musophagaviolaceae, Tauracopersa, Turturafer, Psittaculakrameri. The presence in the past of forest species such as, Bongo (Tragelaphuseurycerus), duikers (Cephalophusspp), mone (Cercopithecus mona), civet (Vivettictiscivetta) and chimpanzee (Pan troglodytes) has been reported. Insects currently represent the most sought-after fauna in the area.The protected area is made up of a mosaic of mesophilic or semi-caducifolia forests and savannahs where species such as Berlinia grandiflora, Pseudospondiasmicrocarpa dominate, Uapacaguineensis, Khaya grandifoliola, Antiarisafricana, Miliciaexcelsa, Triplochitonscleroxylon, Terminalia superba, Cola gigantea, Aubrevilleakerstingii, and Trilepisiummadagascariensis (Adjonou, 2013).

The average annual temperature is $24.3{ }^{\circ} \mathrm{C}$. The monthly average temperature varies from 22.6 ${ }^{\circ} \mathrm{C}$ (July) to $26.3{ }^{\circ} \mathrm{C}$ (February). 


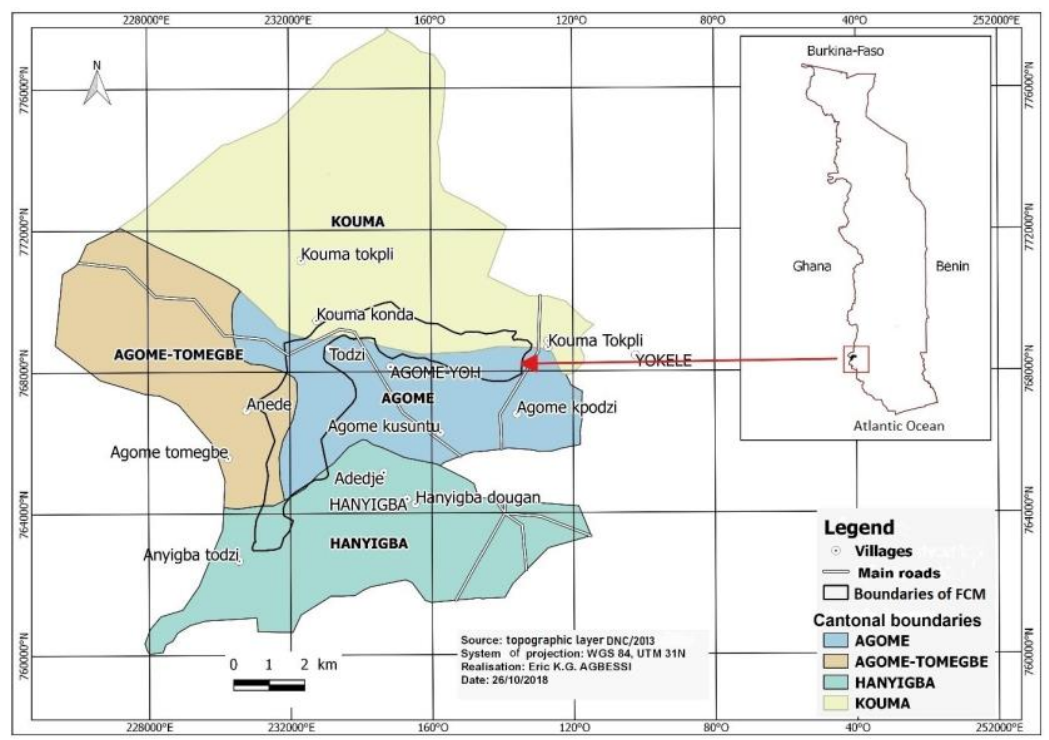

Figure 1. Position of the Protected Area: Missahohe

\subsection{Data and Methodology}

\subsubsection{Data}

The images were downloaded using the United States Geological Survey (USGS) Earth Explorer image servers at http://earthexplorer.usgs.gov/. Three Landsat satellite images corresponding to the years 1986 (Landsat 5), 2001 (Landsat 7) and 2018 (Landsat 8) were used for diachronic analysis, georeferenced database production and thematic maps. The choice of images for these dates was motivated by their availability, their coverage of the study area and their quality. Indeed, the period of image acquisition (December and January) was chosen in order to have cloud-free images because these are the months corresponding to the dry seasons when clouds do not form and especially to reduce the problems related to the change in vegetation phenology. Object of our attention. The years of the images have taken into account the different periods corresponding to the observed increase in anthropic pressure or not. The period of the shooting was also taken into account in order to be able to make an objective comparison between the different dates. 
Vol. 06, No. 01; 2021

ISSN: $2456-8643$

\subsubsection{Method of treatments and analyses}

The analysis of the dynamics of the land occupation was made after the pre-processing of the acquired images, the classification of the images under the software ENVI 5.1, the validation of the classifications and the cartographic restitution. The pre-treatments consisted essentially of choosing the composition of the spectral bands. The study area was then extracted from the scene (193/055) along the boundaries of the classified forest. For classification of the images, the coloured composition was made from channel 4 for infrared, 3 for red and 2 for green according to the colour order red, green, blue. These are the bands that are typically used for land use mapping and vegetation cover dynamics. The training plots were identified through visual interpretation. The training plots were identified through visual interpretation while relying on knowledge of the terrain (the protected area), maps made from high-resolution images (RapidEye) and google earth images (Figure 2). The classification is supervised with the application of the "maximum likelihood" algorithm because of the knowledge of the protected area. Seven land cover classes were identified on the satellite images:

-dense forests, which includes dry dense forests (closed stand with trees and shrubs reaching various heights);

-riparian forests consist of gallery and riparian forests. Riparian forests consist of forest galleries and riparian forests. These are forests along watercourses that are often narrow in width;

-open forests/wooded savannahs (open forests are open stands with small and medium-sized trees with more or less jointed tops, the whole canopy allowing a large amount of light to filter through;

-treed/arboreal savannahs: a variant of savannah in which trees and shrubs are scattered among grassy mats;

-crops/ fallow land: a highly anthropized formation, either by long cultivation or by a succession of crops and fallow land; low density of woody vegetation includes forest fallow land where the height of woody vegetation is less than $5 \mathrm{~m}$. Crops/fallow land corresponds to woody vegetation derived from the clearing of natural forest for shifting cultivation;

-built-up areas: all areas of artificial constructions, dwellings, enclaves, human settlements, and

-bare soil (areas without vegetation, rocky areas).In addition, in order to evaluate the change between different occupancy classes, thePuyravaud (2002) formula was used to determine the annual rate of deforestation. It is expressed as follows:

Txdef $=-\frac{100}{(t 2-t 1)} * \ln \left(\frac{A 2}{A 1}\right)$

Txdef $=$ deforestation rate in $\%, \mathrm{t} 1$ and $\mathrm{t} 2$ : the initial and final years considered for the calculation A1 and A2: the forest areas corresponding to years $\mathrm{t} 1$ and $\mathrm{t} 2$. 


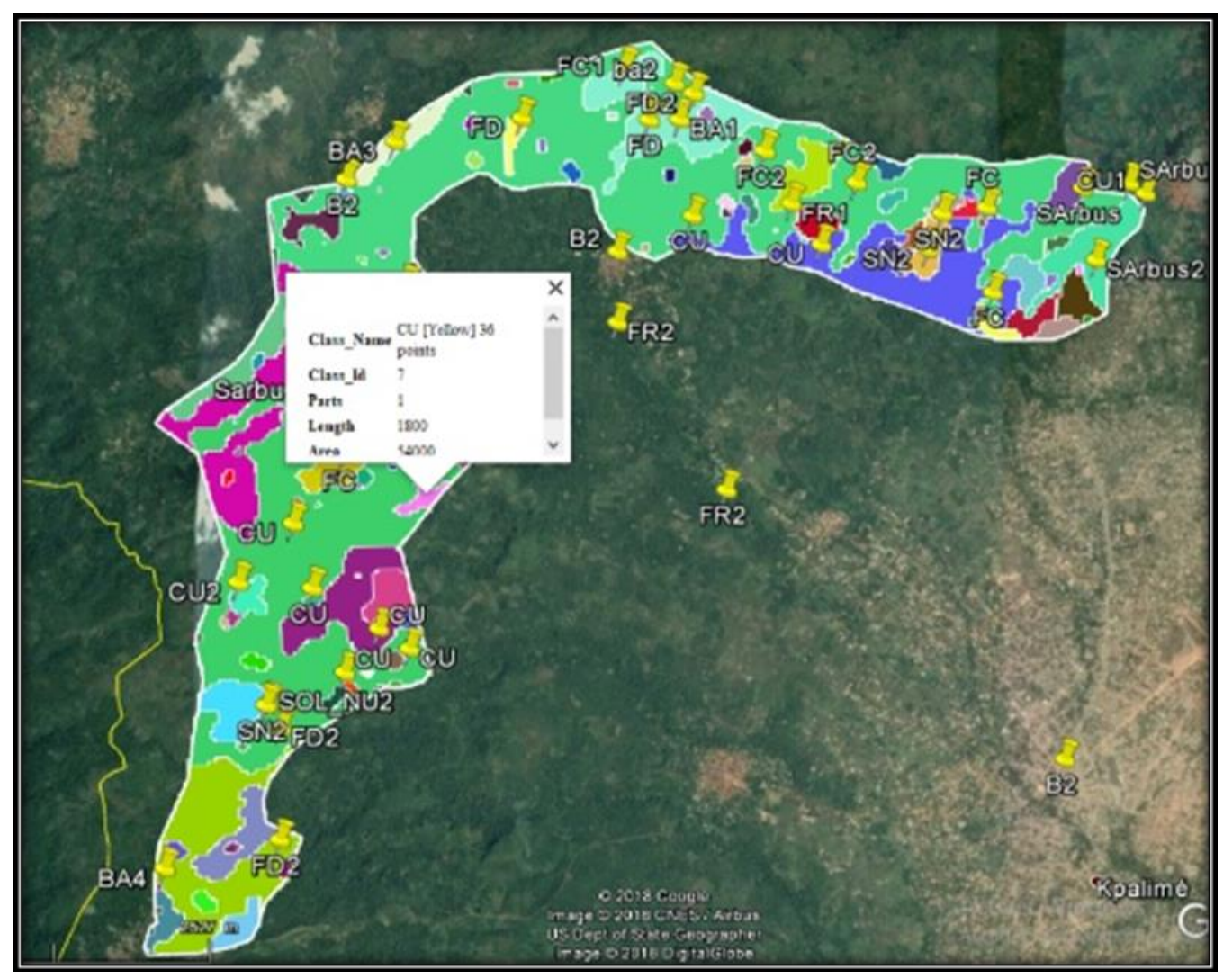

Figure 2. 2018's classification imported into google earth Pro for verification

The training plots identified are representative of the land use classes in the study area. The identified training plots are representative of the land use classes in the study area. The visual interpretation of the spectral curves was done for this purpose. The training plots were evaluated using the contingency matrix, which presents the various confusions between the classes used for classification. The evaluation of the quality of the classification was confirmed by the GPS field check. A sample of more than 250 observations (stratified) for each land use map was made. The classifications were evaluated using the Confusion Matrix by comparing the results of the highresolution maps of the area and the Google Earth Pro images, with the exception of the 1986 classification, which required further analysis of the colour composition and pixel-by-pixel comparison of the classified images for an objective assessment of the changes between 1986 and 2018.

After validation of the classification, the different occupation classes were vectorized and the results were used to develop a georeferenced database under Qgis and the production of thematic maps as well as the various statistics relating to the strata. The comparison of the areas of the different soil occupation units of the periods concerned by the classification and the calculation of the overall rate as well as the annual rate of deforestation made it possible to highlight the dynamics of the vegetation cover between the years 1986 and 2018 of the classified forest. 
Vol. 06, No. 01; 2021

ISSN: $2456-8643$

The Kappa index was used in this study, which evaluates in the confusion matrix the agreement between the results obtained (map) and the truth in the field. It ranges from 0 to 1 , with very weak agreement from 0 to 0.20 ; weak agreement from 0.21 to 0.40 ; moderate agreement from 0.41 to 0.60 ; substantial agreement from 0.61 to 0.80 ; near perfect agreement from 0.81 to 1 .

\section{RESULTS}

\subsection{Map of different units of occupation}

\subsubsection{Quality check of classifications}

The calculation of the classification confusion matrix was done for the three periods considered (1986, 2001 and 2018) for the evaluation of the classifications. The results obtained are recorded in Tables 2, 3 and 4. They present slight non-significant spectral confusions between the different classes.Indeed, dense forests (DF) and riparian forests (FR) are the strata that have been less confused, while crop/ fallow strata and shrubby savannah are significantly confused due to difficulties in discriminating between these two classes because some crop areas left fallow for a long time evolve a savannah in the absence of vegetation fires. The 1986 confusion matrix has an overall accuracy of $89.67 \%$ with a Kappa coefficient of 0.87 . That of 2001 has an overall accuracy of $83.87 \%$ for a Kappa coefficient of 8.80. The confusion matrix of 2018 has an overall accuracy of $96.17 \%$ for a Kappa coefficient of 0.83 . These results are of good quality because according to Pontius (2000), a study on land use can be validated if the Kappa index is between $50 \%$ and $75 \%$.

Table 1. Matrix confusion of year 1986

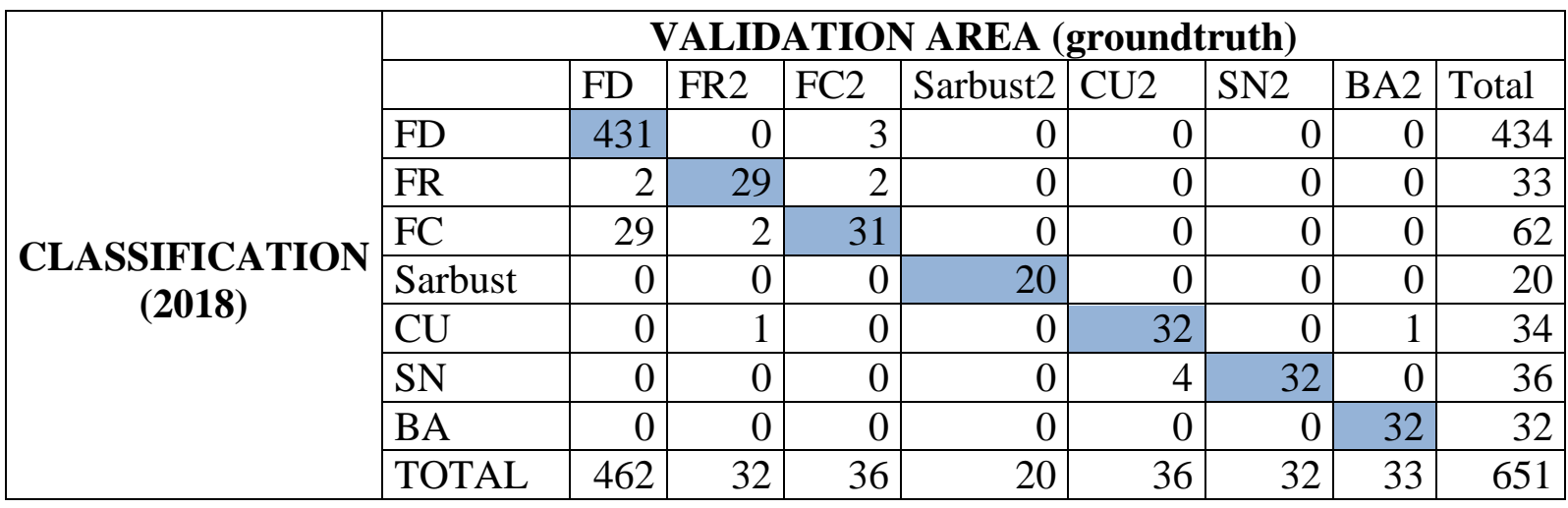

FD: Dense Forest, FC: Open Forest,

FR: Riparian Forest, Sarbust: Shrub Savannah, CU: Crops, SN: Bare soil, BA: Settlements.

Accuracy $=(626 / 651) 96.1598 \%$

Kappa coefficient $=0.83$ 
Table 2. Matrix confusion of year 2001

\begin{tabular}{|c|c|c|c|c|c|c|c|c|c|}
\hline & \multicolumn{9}{|c|}{ VALIDATION AREA (ground truth) } \\
\hline \multirow{9}{*}{$\begin{array}{l}\text { CLASSIFICATION } \\
\text { (2001) }\end{array}$} & & FD & FR2 & $\mathrm{FC} 2$ & Sarbust2 & CU2 & SN2 & BA2 & Total \\
\hline & FD & 32 & 0 & 3 & 0 & 0 & 0 & 0 & 35 \\
\hline & FR & 4 & 30 & 1 & 0 & 1 & 0 & 0 & 36 \\
\hline & $\mathrm{FC}$ & 0 & 2 & 35 & 0 & 0 & 0 & 0 & 37 \\
\hline & Sarbust & 0 & 0 & 0 & 23 & 7 & 1 & 0 & 31 \\
\hline & $\mathrm{CU}$ & 0 & 1 & 1 & 0 & 11 & 4 & 0 & 17 \\
\hline & SN & 0 & 0 & 0 & 0 & 9 & 31 & 0 & 40 \\
\hline & $\mathrm{BA}$ & 0 & 0 & 0 & 7 & 4 & 0 & 72 & 83 \\
\hline & TOTAL & 36 & 33 & 40 & 30 & 32 & 36 & 72 & 279 \\
\hline
\end{tabular}

Accuracy $=(234 / 279) 83.8710 \%$

Kappa coefficient $=0.8069$

Table 3. Matrix of confusion of 2018

\begin{tabular}{|c|c|c|c|c|c|c|c|c|c|}
\hline \multirow{10}{*}{ CLASSIFICATION } & \multicolumn{9}{|c|}{ VALIDATION AREA (groundtruth) } \\
\hline & & FD & FR2 & $\mathrm{FC} 2$ & Sarbust2 & CU2 & SN2 & BA2 & Total \\
\hline & FD & 431 & 0 & 3 & 0 & 0 & 0 & 0 & 434 \\
\hline & FR & 2 & 29 & 2 & 0 & 0 & 0 & 0 & 33 \\
\hline & FC & 29 & 2 & 31 & 0 & 0 & 0 & 0 & 62 \\
\hline & Sarbust & 0 & 0 & 0 & 20 & 0 & 0 & 0 & 20 \\
\hline & $\mathrm{CU}$ & 0 & 1 & 0 & 0 & 32 & 0 & 1 & 34 \\
\hline & SN & 0 & 0 & 0 & 0 & 4 & 32 & 0 & 36 \\
\hline & BA & 0 & 0 & 0 & 0 & 0 & 0 & 32 & 32 \\
\hline & TOTAL & 462 & 32 & 36 & 20 & 36 & 32 & 33 & 651 \\
\hline
\end{tabular}

\subsubsection{Analysis of land use status in 1986 and 2018}

The six land cover classes were identified for the year 1986 and seven of the years 2001 and 2018 (dense forest (DF), open forest (CF), riparian forest (FR), shrubby savannah (Sarbust), fallow (CU), bare soil (SN) and human settlements (BA) that did not exist in 1986 ) were materialized as shown in Figure 4. The Figure 5 shows the dynamics of the different types of land use according to the years. According to the statistics of the 1986 classification, reference date of the study, the protected area (Missahohé classified forest) is characterized by a large area of vegetation marked by clear forests (512 ha), riparian forests (427 ha), dense forests (366ha) which occupy respectively $34 \%, 29 \%$ and $25 \%$ of the total area of the protected area. The tree / shrub savannahs (126 ha), crops / fallow (27 ha) and bare soil (29 ha) are the least represented classes, namely respectively $8 \%, 2 \%$ and $2 \%$. 
In 2001, there was an appearance of buildings that did not exist in 1986. Changes were noted in particular the increase in terms of areas of forest strata like riparian forests that increased from 427 ha (in 1986). For a rate of 29 in 484 ha in 2001 for a rate of 33, an increase of 57 ha.

In addition to riparian forests, the progression of dense forests is perceptible. In fact, the dense forests estimated in 1986 at $25 \%$ increased to $30 \%$ in 2001; an increase of $5 \%$ in 15 years.

The analysis of the results of 2018 reveals a drastic regression of the forest layers (1222 ha in 2018 against 1432 ha in 1986). This is a turnaround compared to the situation observed in 2001 and in 1986 in riparian forests, which are the strata that experienced the greatest decline. Their area increased from 427 ha $(28.73 \%)$ in 1986 to 46 ha $(3.06 \%)$ in 2018. This corresponds to a dynamic of $-89.34 \%$ which reflects a strong anthropic pressure (Table 5).

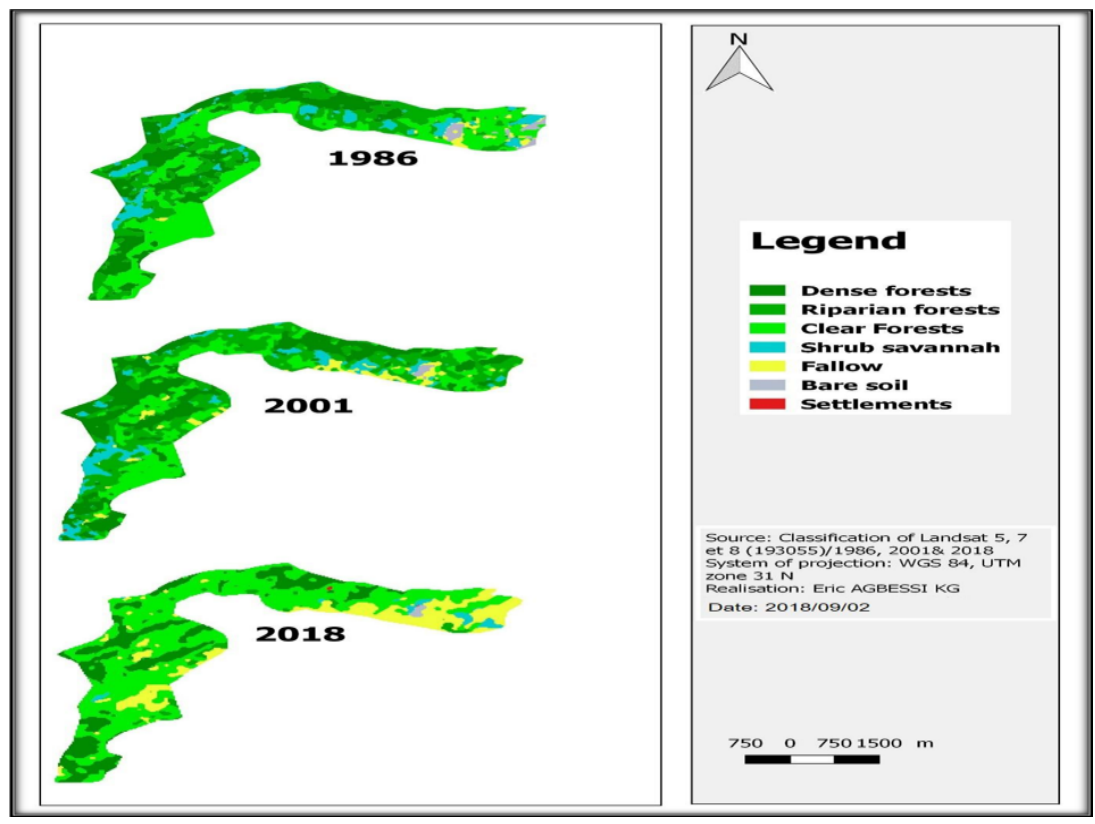

Figure 3. Land cover of the Missahohe classified forest of the years 1986, 2001 and 2018. 


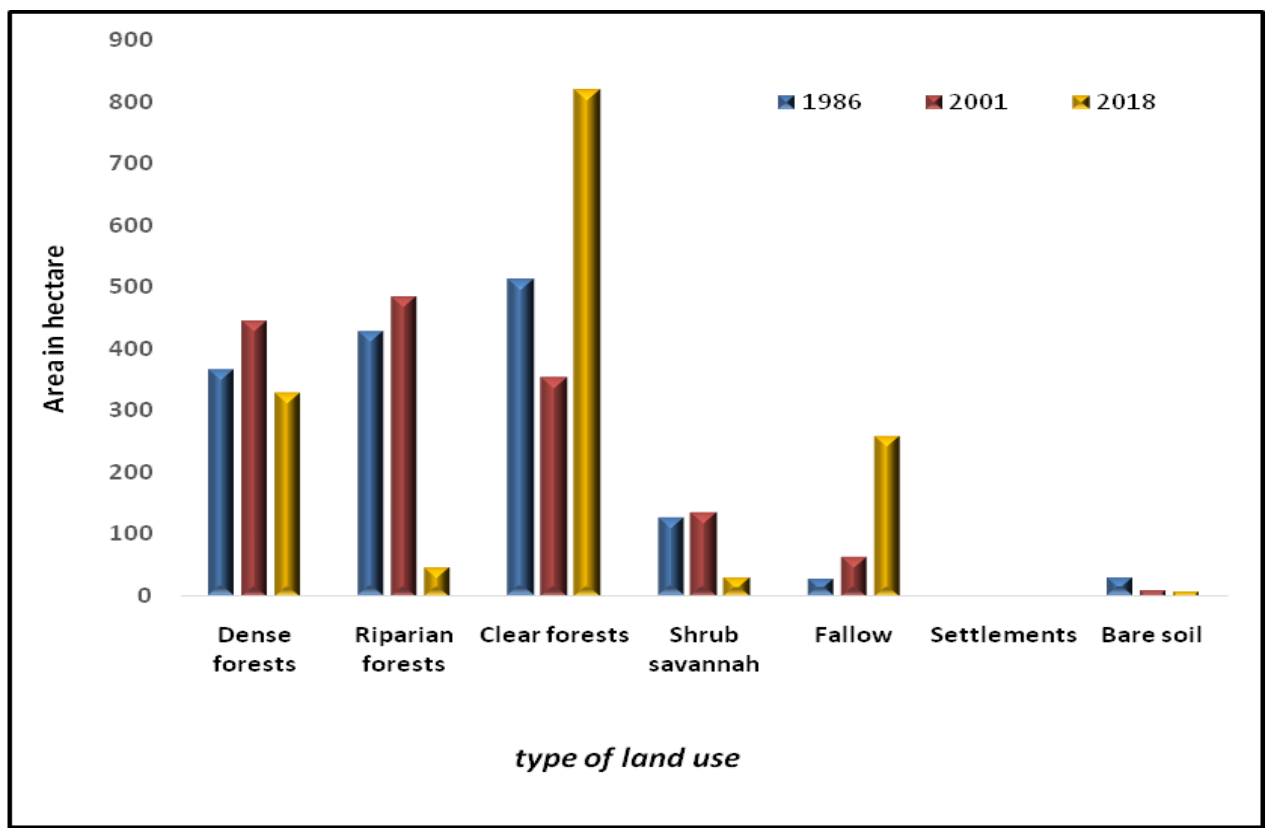

Figure 4. Areas of the different types of land use

Table 4. Land Cover Dynamics of the Missahohe classified forest Protected Area between 1986 and 2018

\begin{tabular}{|c|c|c|c|c|c|c|c|c|c|c|}
\hline \multirow[b]{2}{*}{$\mathbf{N}^{\circ}$} & \multirow[b]{2}{*}{ land cover } & \multirow{2}{*}{$\begin{array}{l}1986 \\
\text { Area } \\
\text { (ha) } \\
\end{array}$} & \multirow{2}{*}{$\frac{1986}{\%}$} & \multirow{2}{*}{$\begin{array}{l}2001 \\
\text { Area } \\
\text { (ha) }\end{array}$} & \multirow{2}{*}{$\frac{2001}{\%}$} & \multirow{2}{*}{$\begin{array}{l}2018 \\
\text { Area } \\
\text { (ha) }\end{array}$} & \multirow{2}{*}{$\frac{2018}{\%}$} & \multicolumn{3}{|c|}{ Dynamics in $\%$. } \\
\hline & & & & & & & & $\begin{array}{l}1986- \\
2001 \\
\end{array}$ & $\begin{array}{l}2001- \\
2018 \\
\end{array}$ & $\begin{array}{l}1986- \\
2018 \\
\end{array}$ \\
\hline 1 & Dense forests & 366 & 25 & 444 & 30 & 328 & 22 & 21.09 & -25.99 & -10.38 \\
\hline 2 & Riparianforests & 427 & 28 & 484 & 33 & 46 & 3 & 13.29 & - 90.59 & -89.34 \\
\hline 3 & Clear forests & 512 & 34 & 354 & 24 & 819 & 55 & 30.77 & 131.28 & 60.105 \\
\hline 4 & $\begin{array}{l}\begin{array}{l}\text { Shrub } \\
\text { savannah }\end{array} \\
\end{array}$ & 126 & 8 & 134 & 9.005 & 29 & 1.918 & 5.96 & 78.70 & -77.43 \\
\hline 5 & Fallow & 27 & 2 & 63 & 4.229 & 258 & 17 & 135.20 & 309.42 & 862.97 \\
\hline 6 & Settlements & 0 & $\mathbf{0}$ & 0.723 & 0.049 & 1.17 & 0.079 & - & 61.87 & - \\
\hline 7 & Baresoil & 29 & 2 & 8 & 0.53 & 7 & 0.468 & 72.69 & -11.66 & -75.88 \\
\hline & Total & 1487 & 100 & 1487 & 100 & 1487 & 100 & & & \\
\hline
\end{tabular}




\subsubsection{Assessment of change: determination of the annual rate of deforestation}

The numerical application of the Puyravaud formula (2002) gives as an annual rate of deforestation:

$$
\text { Txdef }=-\frac{100}{(2018-1986)} * \ln \left(\frac{1221.57}{1431.61}\right)
$$

$t 1=1986, t 2=2018$

$\mathrm{A} 1=1431.61$ ha, $\mathrm{A} 2=1221.57$ hectares, hence the annual rate is equal to $0.5 \%$.

$$
\text { Txdef }=\mathbf{0 . 5 0 \%}
$$

According to the Puyravaud formula, the annual rate of deforestation of the Missahohé classified forest is $0.50 \%$, corresponding to a forest area of about 611 ha. This reflects the intensity of the anthropogenic pressure exerted on the ligneous areas of the protected area from the human settlements which are not supposed to exist there and from the riparian villages which have spread over time to be closer to some metres of protection zones

\section{DISCUSSIONS}

\section{Diachronic analysis of the vegetation cover dynamics of the protected area (1986-2018)}

According to the statistics of the 1986 classification, reference date of the study, the protected area, the Missahohe classified forest is characterized by a large area of vegetation. At that time, according to the classification, there was no human settlement or built. Indeed, since its classification by the decree $n^{\circ} 185-53$ / EF of March 17th, 1953, like the other protected areas, the Missahohé classified forest benefited from a complete and rigorous protection. This has favoured the conservation and evolution of its forest ecosystem. However, the total absence of detection of enclaves or buildings at this time, is due to the fact that almost all of these enclaves are smaller than the size of the pixels $(30 \times 30 \mathrm{~m})$ Landsat images. Because, at the time of the classification of the forest, a few rare enclaves were reported and could persist clandestinely, even if the order of classification stipulated the probable conditions of access to the protected area in order to better control any activity likely to take place there.

Under the terms of Article 4, paragraph 1 of the classification orders, the owners of coffee and cocoa fields inside the forest before the date of classification are authorized to maintain them, and may be authorized by the forest administration to renew them on site. Paragraph 2 of the same article specifies that food crop fields should be transformed into coffee plantations or reforested (MERF, 2010). A provision that excludes de facto neither temporary nor temporary or permanent establishment of human settlements within the protected area.

The analysis in Table 4 shows that in 2001, there was an appearance of buildings that did not exist in 1986. This is predictable due to the lax state of the weakened state and the forest administration. Almost inactive in the field during the social and political unrest of the 1990s. 
Vol. 06, No. 01;2021

ISSN: $2456-8643$

This has favoured the invasion of the protected area by local populations whose concerns have long been ignored. Some of these populations have preferred to install tenants often from the north of the country in search of fertile land for food crops essentially. Other changes have also occurred in other occupancy classes. The most significant are the increases in the area of forest strata, such as riparian forests, which rose from 427.26 ha (in 1986) to 484.1 ha in 2001 , an increase of 56.84 ha.

In addition to riparian forests, the progression of dense forests is noticeable. In fact, dense forests, estimated at $24.63 \%$ in 1986 , rose to $29.82 \%$ in 2001, a slight increase of $5.19 \%$ in 15 years. The conservation of a large part of the dense forest is due to the steep relief in places in the protected area of difficult access and especially to the absence of vegetation fires that sometimes reach these places.

With the exception of clear forests which decreased substantially from 511.71 ha for a rate of $34.4 \%$ in 1986 to 354.2 ha for a rate of $23.83 \%$ in 2001, and bare soils also declined in 2001, the other classes of occupations (savannahs / shrubs, and crops / fallows) showed a slight increase. Their rate increases from $8.5 \%$ and $1.8 \%$ respectively (in 1986) to $9 \%$ and $4 \%$ (2001). The progress of dense and riparian forests could be explained by a small negative impact following the invasion of the area by populations that had a relatively smaller population and whose human activities were limited to those times in the field work with small areas cultivated and forest exploitation certainly but in a traditional way.

Today, an opposite phenomenon is taking place in the entire region of southwestern Togo, which is seeing renewed interest in food crops, abandoned in favour of cash crops (Tchamiè, 2000). Most of the farmers were settled there by the families of the former landowners prior to grading and were rather concerned about the maintenance and operation of their coffee and cocoa plantation and other types of farms just like the products. Non-timber forest products (NTFPs) that are not strictly prohibited. In its natural habitat, the coffee tree is found in shady or semishaded situations. Its behaviour with regard to the light made it long to consider like a plant heliophobe, demanding in the plantation a cover more or less dense (Tchamiè, 2000).

In addition, the Plateaux region known as the forest region of Togo, constitutes a very attractive pole, tourist with its wonderful landscape arousing very important craze (frequency of visits of the nationals and the Europeans very high). This factor amplified by some state projects of awareness and reforestation (More than 1000 ha reforested at the end of the 90s) allowed the local populations to quickly become aware through interests and benefits they derive from the implementation of the various afforestation projects as well as from the exploitation of their coffee and cocoa plantations as well as non-timber forest products dependent on the protection of forest layers (Lepidopterophilia for commercial purposes, honey, spices, fruit, mushroom fodder, firewood, crop medicinal plants, small cola, etc.). However, a comparison of the forest areas of dense, clear, riparian forests and tree / shrub savannahs (1431.61 ha in 1986 compared to 1417.70 ha in 2001) shows a slight regression of the forest strata of $15.91 \mathrm{ha}$.

The analysis of the results of January 2018 reveals a drastic regression of the forest layers (1221.57 ha in 2018 against 1431.61 ha in 1986). This is a turnaround compared to the situation observed in 2001 and in 1986 in riparian forests, which are the strata that experienced the 
Vol. 06, No. 01; 2021

ISSN: $2456-8643$

greatest decline. Their area increased from 427.26 ha (28.73\%) in 1986 to 45.54 ha (3.06\%) in 2018. This corresponds to a dynamic of $-89.34 \%$ which reflects a strong anthropic pressure. These results are similar to those obtained by Kpédénou (2016) in the maritime region of the country.

In addition to the riparian forests, the other forest layers experienced no less significant regression except for the clear forest which saw its area increased from 511.71 ha in 1986 to 819.27 ha in 2018, most of which would result from the degradation of dense forests and riparian forests. The strong pressures observed at the level of the dense forest are translated by its dynamics which is of $-10.38 \%$. Following the wooded savannahs / shrubs with the dynamics of $77.43 \%$ in favour of the crops / fallows (which continues to grow impressively over time with a dynamic of $+862.97 \%)$.

Buildings from 2001 also evolve and follow the rate of crop / fallow growth for an area starting from zero (in 1986) to 1.17 ha (in 2018) or more when considering their small size. Less than the objects that Landsat imagery can detect. The bare soils have decreased slightly from $1.94 \%$ in 1986 to $0.74 \%$ in 2018 , probably due to their recovery over time by vegetation. The regression observed at the level of the forest layers, in particular, the dense and riparian forests, is attributable to the demographic pressure that has grown since these periods until today. These results confirm those of the work of Kpédénou (2016) and ONF International (2018), which demonstrated the same trend under similar conditions. As the needs are increased as the population grows, the old farmlands become infertile and insufficient, the local populations have no choice but to fall back on the preserved and fertile areas to extend their fields.

According to the 2012 national agricultural census, the Plateaux region alone accounts for nearly $32 \%$ of farm households in all five administrative regions of the country.

Added to this is the proliferation of several charcoal burners and the development of logging operations, which are almost entirely for export through sawmills, whose number has increased over the past ten years. The concern for the maintenance and exploitation of coffee and cocoa plantations has diminished with the fall in the price of coffee and cocoa, their poor performance in terms of climate variability and in particular the introduction of new varieties of coffee. Coffee (robusta coffee for example) requiring thinning and not shading as was the case of older varieties in the past.

The easy gain has won hearts and logging has become an important activity for these local populations who think they can earn better and without much difficulty their lives thanks to logs and logs from fraudulent logging cuts. Intensive export operations led the Togolese government to establish a ten-year moratorium on 22 June 2016 on the exploitation, import and re-export of veneer logs (Pterocarpus erinaceus) in order to reduce the impact that its overexploitation generates on the environment.

\section{CONCLUSION}

The present study has made it possible to better understand the evolutionary dynamics of the plant cover of the Missahohé classified forest and its state of conservation until 2018 from a 
Vol. 06, No. 01; 2021

ISSN: $2456-8643$

diachronic analysis likely to guide the development of a conservation and management strategy. Sustainable management of resources (management plan). It has also made it possible, thanks to geomatic tools and methods, to highlight seven units of occupation, namely dense forest, riparian forest, wooded forest or savannah, tree or shrub savannah, forest crop / fallow, bare soil and settlements. The spatial and temporal analysis shows that the protected area, the Missahohé classified forest, is marked by a strong degradation of its forest ecosystem due to human activities. The area of the forest layer (dense, clear, riparian forest and savannah) has experienced an unprecedented decline. It has decreased from 1431.61 ha in 1986 to 1221.57 ha in 2018 for a deforestation rate of $0.5 \%$. Agriculture, particularly food crops, illegal logging, and carbonization, which is amplified by laxity and the lack of resources of the local forest administration, are the main factors causing the degradation or even the deforestation of the forest. Missahohé Classified Forest. The alteration of the forest ecosystem has led to significant disturbances of certain animal habitats, or even their disappearance, as well as the loss of plant biodiversity in favour of food crops and buildings. Actions to conserve the forest heritage of the protected area are therefore worthwhile to try to reverse the trend.

\section{REFERENCE}

Achard F., Ansseau C., Beaubien J., Defourny P., Jaton A., Lemieux G., Royer A. \& Thomson K. (1996):Remotesensing of forests. In: AUPELF et al. (Editor). Summary of Remote Sensing Volume II. AUF, Quebec, pp. 227-265.

Adjonou K., Kokutse A. D. and Kokou K. (2013): Spatial dynamics and floristic diversity of the Togodo Wildlife Reserve in South East Togo (West Africa). Scripta Botanica Belgica, 50: 6372.

Afélu B. \&Kokou K. (2015): Physical parameters for evaluating the behavior of wildfires in Togo. International Journal of Biological and Chemical Sciences 9 (4): 2091-2105. DOI: http://ajol.info/index.php/ijbcs

Barima Y., Barbier N., Bamba I., Traore D., Lejoly J. and BogaerT J., (2009): Landscape dynamics in the midst of Ivorian forest-savanna transition. In: Bois et forêt des tropiques, Editions Cirad, Montpelier, Vol. 63, ${ }^{\circ}$ 299, pp. 15-25.

Caloz, R. i\& Collet, C. (2001): Precise in remote sensing. Digital Remote Sensing Image Processing, Volume 3. ISBN 2-7605-1145-6 400P.

Dudley N. (2008): Guidelines for the application of management categories to protected areas. Gland, Switzerland: IUCN. 99p.

Enonzan F. B. (2010): Use of remote sensing and GIS in the sustainable management of protected areas: the case of classified forests of Dogo-Ketou in Benin. Specialized Higher Studies Diploma (DESS) at RECTAS Obafemi Awolowo University Campus Ilé-Ifè, Nigeria, 73 p.

Ern, H. (1979): Die Vegetation Togo. Gliederrung, Gefahrdung, Erhatung. Willdenowia 9, 295312. 
Vol. 06, No. 01; 2021

ISSN: $2456-8643$

Ernoul L., Sandoz A., Fellague A. (2012): The evolution of two great Mediterranean Deltas: Remote sensing to visualize the evolution of habitats and land use in the Gediz and Rhone Deltas. Ocean \& Coastal Management 69 (2012) 111-117.

FAO (1990): Forest resources assessment. Survey of tropical forest cover and study of change processes. Forestry Paper, 130, Roma, 152 pages.

FerkaZazou N., (2006): Impact of the spatiotemporal occupation of spaces on the conservation of the forest ecosystem: case of the Municipality of Tessala, wilaya of Sidi Bel Abbes, Algeria. Magisterium thesis, University of Tlemcen, Algeria, 129 p.

Heymann Y., (1978): Inventories of natural resources by satellite remote sensing. In Rural Economy, Revue de la Société Française d'Economie Rurale (SFER), Paris, $\mathrm{n}^{\circ} 127$, Ecologie et société, Part II, pp. 31-34.

INSEED. (2010): Fourth general population and housing census. Special volume. Lomé, 238 pages. Kokou K., (1998-a): Management of patches of natural forests by village communities in Togo. In: Flamboyant, SILVA RIAT, $\mathrm{n}^{\circ} 45$, Paris, pp. 47-52.

Kokou K., (1998-b): Forest mosaics in southern Togo: biodiversity, dynamics and human activities. Doctoral thesis in Biology of populations and ecology, University of Montpelier II, Montpelier, 149 p.

Kokou K., Afiademanyo K., \&Akpagana K. (1999): Sacred coastal forests of Togo: cultural role and biodiversity conservation. In: J. Rech. Sci. Univ. Benin, Vol. 3, n ${ }^{\circ}$ 2, Lomé, pp. 91-104.

Kpédénou KD, Drabo O., Ouoba AP, DA Dapola CE, \&Tchamiè TTK (2017): Analysis of land use for monitoring the evolution of the landscape of the Ouatchi territory in south-eastern Togo between 1958 and 2015. In: Presses de l'Université de Ouagadougou CAHIERS DU CERLESH XXXI, no 55, Ouagadougou, pp. 203-28.

Menon, S. \&Bawa K.S. (1997): Application of geographic information systems, remote sensing, and landscape ecology approach to biodiversity conservation in Western Ghats. Curr.Sci, 75 : pp $228-285$.

FerkaZazou N., (2006): Impact of the spatiotemporal occupation of spaces on the conservation of the forest ecosystem: case of the Municipality of Tessala, wilaya of Sidi Bel Abbes, Algeria. Magisterium thesis, University of Tlemcen, Algeria, 129 p.

Heymann Y., (1978): Inventories of natural resources by satellite remote sensing. In Rural Economy, Revue de la Société Française d'Economie Rurale (SFER), Paris, n ${ }^{\circ} 127$, Ecologie et société, Part II, pp. 31-34.

INSEED. (2010): Fourth general population and housing census. Special volume. Lomé, 238 pages. Kokou K., (1998-a): Management of patches of natural forests by village communities in Togo. In: Flamboyant, SILVA RIAT, $\mathrm{n}^{\circ} 45$, Paris, pp. 47-52. 
Vol. 06, No. 01; 2021

ISSN: $2456-8643$

Kokou K., (1998-b): Forest mosaics in southern Togo: biodiversity, dynamics and human activities. Doctoral thesis in Biology of populations and ecology, University of Montpelier II, Montpelier, $149 \mathrm{p}$.

Kokou K., Afiademanyo K., \&Akpagana K. (1999): Sacred coastal forests of Togo: cultural role and biodiversity conservation. In: J. Rech. Sci. Univ. Benin, Vol. 3, n ${ }^{\circ}$ 2, Lomé, pp. 91-104. Kpédénou KD, Drabo O., Ouoba AP, DA Dapola CE, \&Tchamiè TTK (2017): Analysis of land use for monitoring the evolution of the landscape of the Ouatchi territory in south-eastern Togo between 1958 and 2015. In: Presses de l'Université de Ouagadougou CAHIERS DU CERLESH XXXI, no 55, Ouagadougou, pp. 203-28. 